\title{
Effects of alcoholic extract of Myristica fragrans (nutmeg) on pregnancy outcome in female Wistar rats
}

\author{
SAKPA, CL; ${ }^{*}$ EGUAVOEN, DO \\ Department of Anatomy, University of Benin, Benin City, Edo State, Nigeria \\ *Corresponding Author Email: Edesmond166@gmail.com; Other Author email: sakpachristopher@yahoo.com
}

\begin{abstract}
Myristica fragrans has been reported to be a medicinal plant as it possesses hepatoprotective, antimicrobial, anti-oxidant, antiulcer, anticancer and immunostimulatory properties, as well as antifertility potentials. This study therefore aimed to investigate the effects of alcoholic extract of $M$. fragrans on dam size, litter size, pup weight, ovarian follicles, endometrial glands and histopathological indices on pregnancy outcomes in female Wistar rats using standard methods. Pregnancy was induced in forty-eight (48) female Wistar rats that were randomly selected and assigned into four (4) groups of twelve (12) rats each: Group 1 (pregestational phase of pregnancy), Group 2 (germinal phase of pregnancy), Group 3 (embryonic phase of pregnancy) and Group 4 (Fetal phase of pregnancy). The treated animals all received $1500 \mathrm{mg}$ of alcoholic extract of M. fragrans. Administration of distilled water and the extract was by orogastric tube. Data were subjected to statistical analysis using the IBM SPSS statistics software (Statistical Package for Social Science) (Version 25) and relevant statistical values were obtained. The extract prevented the proliferation of ovarian follicles and endometrial glands. In addition, during the pregestational, germinal and embryonic phases, there were significant increases in weight of pups when the treated animals were compared to the control group. The dams also showed decreases in body weight during the embryonic phase. This study therefore demonstrated that alcohol extract of Myristica fragrans may serve as a contraceptive agent in view of its anti-fertility effect.
\end{abstract}

\section{DOI: https://dx.doi.org/10.4314/jasem.v25i8.31}

Copyright: Copyright $\odot 2021$ Sakpa and Eguavoen. This is an open access article distributed under the Creative Commons Attribution License (CCL), which permits unrestricted use, distribution, and reproduction in any medium, provided the original work is properly cited.

Dates: Received: 10 May 2021; Revised: 28 June 2021; Accepted: 01 July 2021

Keywords: Myristica fragrans, uterus, ovary, pregnancy, Wistar rats.

Medicinal plants are plants that provide healthpromoting characteristics, provide temporary relief of symptoms or have curative properties (Calixto, 2000). The use of plant herbs and other natural products for the restoration of health dates back to ancient times. The earliest known medical document is a 4000-yearold Sumerian clay tablet that recorded plant remedies for various illnesses. Industrialized nations are developing interest in the use of herbs. In the United States, increasing public dissatisfaction with conventional medicine and its increased cost, combined with an interest in returning to natural or organic remedies with the mistaken impression that natural products are safe, has led to an increase in the use of herbal medicines (Zhang et al., 2015). Herbal medical practice has been the main form of treatment especially among indigenous populations around the world particularly in developing countries, and the World Health Organization has also estimated that $80 \%$ of people worldwide rely on herbal medicines for some aspect of their primary healthcare (WHO, 2005). In Germany it is estimated that roughly 600 to 700 plant-based medicines are available and are prescribed by approximately $70 \%$ of German physicians and herbal medicines are actually prescribed more often than conventional medicines. These plant-based medicines have been studied and the claims of a number of compounds in them shown to be valid while others have been ineffective or more toxic than prescription alternatives (Schulz et al., 2001). Plants that were considered of no value are now being investigated, evaluated, and developed into drugs with little or no side effects (Lahlou, 2013). Fertility regulation with plant preparations has been reported in ancient literature of indigenous systems of medicine. Several animal studies have revealed anti zygotic, blastocytotoxic, anti-implantation and abortifacient properties of water and organic solvent extracts of many commonly used medicinal plants, sometimes in dose dependent manner. Practice of nutmeg as a spice in food preparation and as a medication for common sicknesses such as biliousness, vomiting, and diarrhea is centuries ancient (Odebiyi and Sofowora, 1978). In Chinese medicine, nutmeg is used to treat abdominal pain, diarrhea, inflammation, impotence, liver disease, and vomiting (De Milto and Frey, 2019). In the Middle East, some cultures are said to use nutmeg in love potions as an aphrodisiac. The essential oil of nutmeg is used for rheumatic pain, toothaches, and bad breath. In Germany, it is used for problems 
related to the stomach and intestines, but this use is controversial. In homeopathy, nutmeg is used to treat anxiety or depression (De Milto and Frey, 2019). In Nigeria, it is commonly used as a spice and its sometimes abused because of its aphrodisiac effects. Although nutmeg has been used to treat many ailments, it hasn't been proven to be useful or effective for any and it can be harmful (De Milto and Frey, 2019). Myristica fragrans Houtt (Nutmeg) is a tropical, dioecious evergreen tree native to the Moluccas, of the Spice Islands of Indonesia. The nutmeg plant, is a member of the small primitive family called Myristicaceae, taxonomically placed between Annonaceae and Lauraceae (Joseph, 1980). Myristicaceae is considered a member of Magnoliales or its taxonomical equivalents (Cronquist and Takhtadzhian, 1981). The name nutmeg comes from Latin, nux muscat, meaning musky nut. Legend has it that when $M$. fragrans sets seed, the musky smell of the nutmegs is so overpowering that it causes birds of paradise to fall to the ground. This may have more to do with the narcotic properties of nutmeg than with its characteristic scent, but it is this musky quality that has made nutmeg a popular flavouring for both sweet and savoury dishes (Nagano, 2009). Pharmaceutically, nutmeg has been accepted because of its anti-swelling, as well as antithrombotic properties (Olajide et al., 1999). In addition, it also possesses anti-rheumatic and stimulatory properties (Prabuseenivasan et al., 2006). Nutmeg has also been known for its psychoactive properties of producing anxiety/fear and hallucinations from as early as the 16th century (Brenner et al., 1993). This study therefore aimed to investigate the effects of alcoholic extract of Myristica fragrans on pregnancy outcomes in Wistar rats.

\section{MATERIALS AND METHOD}

Plant material: The seeds of $M$. fragans were identified at the Herbarium of the Department of Plant Biology and Biotechnology, Faculty of Life Sciences, University of Benin, Nigeria. They were obtained from the Egor Local Government Area of Edo State, Nigeria. The seeds were shade-dried for seven (7) days, after which they were pulverised into powder form using a mechanical grinder and weighed using electrical weighing balance. Extraction was carried out by established methods (Eze and Akonoafua, 2019).

Experimental animals: Forty-eight (48) mature female Wistar rats were sourced from the Animal house of the Department of Anatomy, School of Basic Medical Sciences, University of Benin, Benin- City, Edo State. The experimental animals were about $10-12$ weeks old, weighing between $200 \mathrm{~g}-250 \mathrm{~g}$ at the onset of the study. Throughout the period of this study, the animals were housed in the Animal House of the Department of Anatomy, University of Benin. Two weeks (14 days) of acclimatization preceded the commencement of the study proper. All animals received food and water ad libitum for the entire duration of the experiment.

Induction of pregnancy: The forty-eight (48) female Wistar rats were randomly selected and housed two per cage with a matured male Wistar rat of proven fertility ( 2 females with 1 male in a cage), for a period of four (4) days, to ensure that all the female rats get pregnant.

Animal grouping and treatment: Forty-eight (48) female Wistar rats were randomly assigned into four (4) groups of twelve (12) rats each and labeled as follows:

1. Pre gestational administration (Group 1): comprising of twelve (12) rats with six (6) being the control to be treated before the induction of pregnancy. 2. Germinal phase of pregnancy administration (Group 2): comprising of twelve (12) rats with six (6) being the control to be treated between day 1 to 7 .

3. Embryonic phase of pregnancy administration (Group 3): comprising of twelve (12) rats with six (6) being the control to be treated between day 8 to 15 .

4. Fetal phase of pregnancy administration (Group 4) comprising of twelve (12) rats with six (6) being the control to be treated between day 16 to delivery.

The treatment sub-groups were given $1500 \mathrm{mg}$ extract of $M$. fragrans while the control received $1 \mathrm{ml}$ of distilled water.

Sacrifice, tissue collection, processing and staining: After the treatment period, the animals were euthanized under chloroform anesthesia. The uteri and ovaries were harvested and cleared of connective tissues. Thereafter, the organs were fixed in freshly prepared phosphate buffered saline. Staining of tissues was done by established methods (Drury et al., 1976).

Photomicrography: Stained slides were viewed using an optical photomicroscope (Leica MC170 HD, Leica Biosystems, Germany) and photomicrographs were taken at x100 magnification using an attached Eakins 14MP digital microscopic camera, model 2307su, manufactured by Eakins Microscope Store, UK.

Counting of ovarian follicles and endometrial glands in H\&E-stained uterine sections: Counting of ovarian follicles and endometrial glands were done using the Image-J software (Fiji) version 1.52, National Institutes of Health, USA. 
Statistical analyses: All data were subjected to statistical analysis using the IBM SPSS statistics software (Statistical Package for Social Science) Version 25 (SPSS, inc., Chicago, Illinois, USA) and relevant statistical values were obtained. The values of the treated groups were compared with those of nontreated group using the one-way analysis of variance (ANOVA) and the T-test method. Values of $\mathrm{P}<0.05$ were considered significant. LSD was used as the posthoc test.

\section{RESULTS AND DISCUSSION}

Pregestational phase: Change in body weight: The results comparing the initial and final body weight of dams in the pregestational stage showed that there was no significant difference $(p>0.804)$ between the treated group when compared to the control group.

Litter size: There was no significant difference ( $>0.184$ ) when the litter size was compared to the control group.

Pup weight: When comparing the birth weight of the pups, it was observed that there was a significant difference $(\mathrm{p}<0.027)$ when the treated pup weights were compared to the control group.

Germinal phase: Change in body weight: The change between the initial and final body weight of dams in the germinal phase of the treated group showed no significant difference ( $p>0.05)$ when compared to the control group.

Litter size: There was no significant difference $(p>0.05)$ when the litter size of the treated groups was compared to the control group.
Pup weight: Comparing the birth weight of the pups, showed that there was a significant difference $(p<0.05)$ when the pup weight of the treated groups was compared to the control groups.

Embryonic phase: Change in body weight: The change between the initial and final body weight of the dams in the embryonic stage showed that there was a significant difference $(\mathrm{p}<0.05)$ when the initial and final body weights of the treated group were compared to the control group.

Litter size: There was a significant difference $(\mathrm{p}<0.05)$ when the litter size of the treated group was compared to the control group.

Pup weight: When comparing the birth weights of the pup, it was observed that there was a significant difference $(\mathrm{p}<0.05)$ when the pup weights of the treated group were compared to the control groups.

Fetal phase: Change in body weight: The change between the initial and final body weight of dams in the fetal stage showed no significant difference $(p>0.05)$ when the treated groups were compared to the control group.

Litter size: There was no significant difference $(p>0.05)$ when the litter size of the treated group was compared to the control group.

Pup weight: Comparing the weight of pups, it was observed that there was no significant difference ( $>0.05)$ in the birth weight of the treated groups when compared to the control group.

Table 1: Showing the mean values of parameters of experimental animals during the pre-gestational phase.

\begin{tabular}{llll}
\hline \multicolumn{4}{l}{ Pre-gestational Phase } \\
\hline PARAMETERS & Control & Treated Group & P-Value \\
\hline Weight change in dams (g) & $2.00 \pm 0.81$ & $1.17 \pm 0.9$ & 0.804 \\
\hline Litter size & $7.00 \pm 0.58$ & $5.00 \pm 0.58$ & 0.184 \\
\hline Pup weight (g) & $6.36 \pm 0.14$ & $5.69 \pm 0.0$ & $0.027^{*}$
\end{tabular}

Values are represented as Mean \pm SEM; *indicates significant difference $(P<0.05)$ compared to control.

Table 2: Showing the mean values of parameters tested in the experimental animals during the germinal phase.

\begin{tabular}{llll}
\hline \multicolumn{4}{l}{ Germinal Phase } \\
\hline PARAMETERS & Control & Treated Group & P-Value \\
\hline Weight change in dams $(\mathbf{g})$ & $6.00 \pm 0.76$ & $5.00 \pm 1.00$ & 0.651 \\
\hline Litter size & $6.67 \pm 0.33$ & $4.67 \pm 0.33$ & 0.074 \\
\hline Pup weight $(\mathbf{g})$ & $6.42 \pm 0.07$ & $5.07 \pm 0.16$ & $0.001^{*}$ \\
\hline represented as Mean \pm SEM; $*$ *indicates significant difference $(P<0.05)$ compared to control
\end{tabular}

Values are represented as Mean \pm SEM; *indicates significant difference $(P<0.05)$ compared to control

Table 3: Showing the mean values of parameters tested in the experimental animals during the embryonic phase.

\begin{tabular}{llll}
\hline \multicolumn{4}{l}{ Embryonic Phase } \\
\hline PARAMETERS & Control & Treated Group & P-Value \\
\hline Weight change in dams (g) & $11.00 \pm 1.59$ & $-0.50 \pm 0.61$ & $0.031^{*}$ \\
\hline Litter size & $7.67 \pm 0.33$ & $5.33 \pm 0.33$ & $0.020^{*}$ \\
\hline Pup weight (g) & $6.52 \pm 0.13$ & $4.44 \pm 0.19$ & $0.000^{*}$ \\
\hline
\end{tabular}

Values are represented as Mean \pm SEM; *indicates significant difference $(P<0.05)$ compared to control 
Table 4: Showing the mean values of parameters tested in the experimental animals during the fetal phase.

\begin{tabular}{llll}
\hline \multicolumn{3}{l}{ Fetal Phase } & \\
\hline PARAMETERS & Control & Treated Group & P-Value \\
\hline Weight change in dams $(\mathbf{g})$ & $5.67 \pm 1.03$ & $3.50 \pm 0.5$ & 0.555 \\
\hline Litter size & $7.33 \pm 0.33$ & $6.00 \pm 0.31$ & 0.741 \\
\hline Pup weight $(\mathbf{g})$ & $6.39 \pm 0.08$ & $6.38 \pm 0.14$ & 0.956 \\
\hline
\end{tabular}

Values are represented as Mean \pm SEM; *indicates significant difference $(P<0.05)$ compared to control.

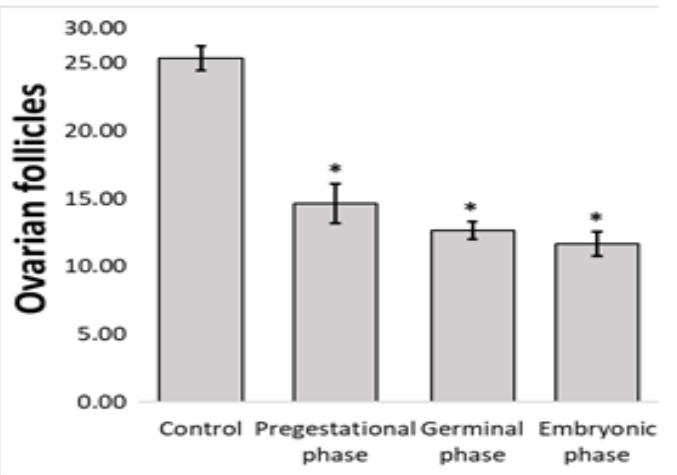

Fig 2: Chart showing the effect of M. fragrans on the number of endometrial glands.

There were no significant differences $(P<0.05)$ in the number of endometrial glands when the treated groups were compared to the control group

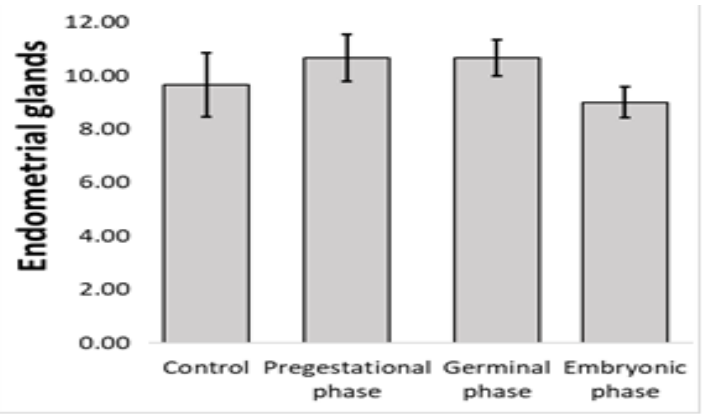

Fig 2: Chart showing the effect of M. fragrans on the number of endometrial glands

There were no significant differences $(P<0.05)$ in the number of endometrial glands when the treated groups were compared to the control group

Histology of the ovary and uterus: Plates 1 and 2 are photomicrographs of ovaries of the control group at $\mathrm{x} 40$ and $\mathrm{x} 100$ magnifications, respectively. They show normal coelomic epithelium, follicles in various stages, luteinized stroma and blood vessel. Plates 3, 4, 5 and 6 are photomicrographs of rat ovaries given $M$. fragrans from day 0-6 and sacrificed on day 14 . They show follicles at various stages, luteinized stroma, atretic follicles and moderate active stromal congestion. Plates 7 and 8 are photomicrographs (at x40 and x100 magnifications, respectively) of rat ovary given $M$. fragrans from day 7-14 and sacrificed on day 19. They show secondary follicles, stromal congestion and luteinized stroma. Plates 9 and 10 are photomicrographs of rat ovary at the pregestational phase, showing stromal congestion and increased folliculogenesis. Plates 11 and 12 are photomicrographs (at x40 and x100 magnifications, respectively) of rat uterus from day 0-7 at R-site showing endometrial lining forming villi, glandular cell hyperplasia, stromal cell hyperplasia and active congestion. Plate 13 is also a photomicrograph of rat uterus from day 0-7 at R-site, but shows villous endometrial lining, hypertrophic stromal cells, proliferating glands, active vascular congestion and haemorrhage. Plates 14, 15, 16 and 17 are photomicrographs of rat uterus, from day 0-7 showing stromal cell vacuolation, prominent nucleoli of stromal cells and endometrial lining thinning-atrophy. Plates 18 and 19 are photomicrographs (at x40 and x100 magnifications, respectively) of rat uterus, of day 7-14 space, showing myxoid stroma, stromal congestion and myometrial hypertrophy. Plates 20 and 21 are photomicrographs (at $\times 40$ and $\times 100$ magnifications, respectively) of rat uterus, at day 0-7 space, showing myxoid stroma, blood in cavity, stromal congestion and glandular atrophy, while Plates 22 and 23 show rat uteri, at day 7-14 space, exhibiting myxoid stroma, congestion and myometrial hypertrophy.

\section{Photomicrographs of $H \& E$ stained sections}

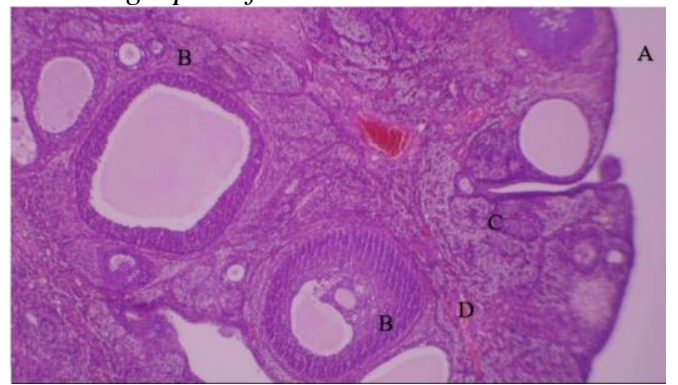

Plate 1: Control rat ovary showing A: coelomic epithelium, B: follicles in various stages, C: luteinized stroma and D: blood vessel (H\&E x 40)

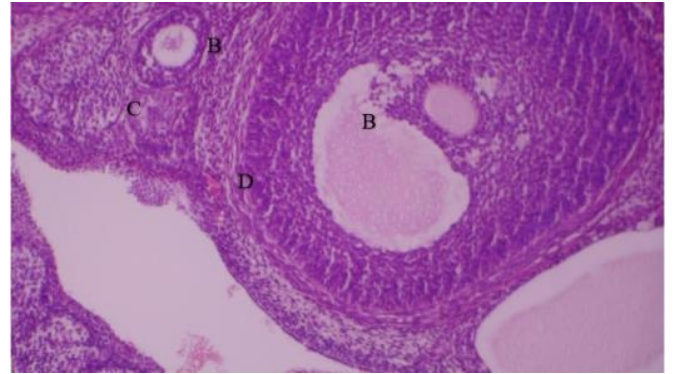

Plate 2: Higher magnification of same slide: $B, C$ and D (H\&E x 100) 


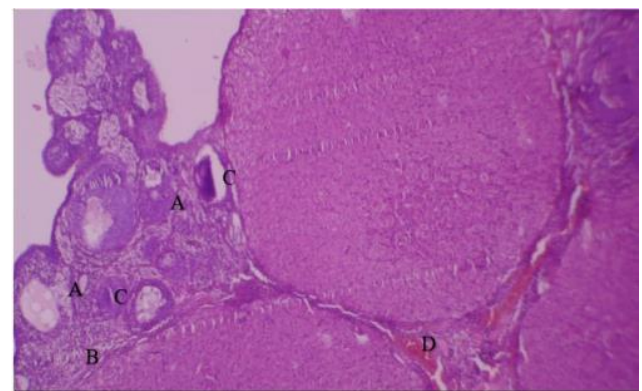

Plate 3: Rat ovary given nutmeg day 0-6, sacrificed day 14 showing A: follicles at various stages, B: luteinized stroma, C: atretic follicles and D: moderate active stromal congestion (H\&E $\mathrm{x}$ 40)

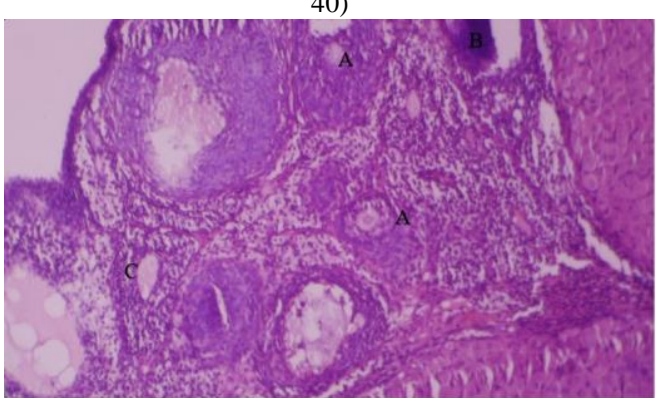

Plate 4: Higher magnification of same slide: A, B, C (H\&E x 100)

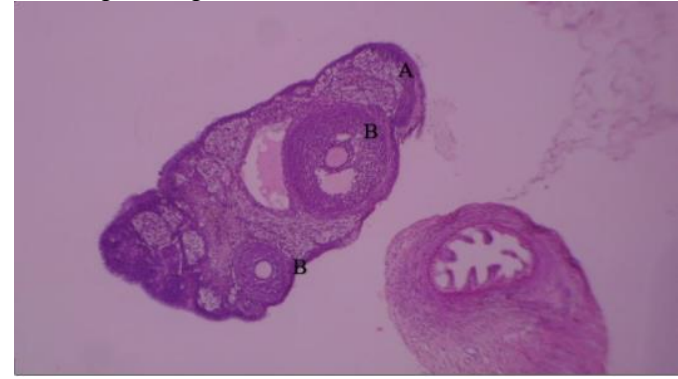

Plate 5: Rat ovary, same group day 0-6 showing A: luteinized stroma and B: follicles at various stages (H\&E x 40)

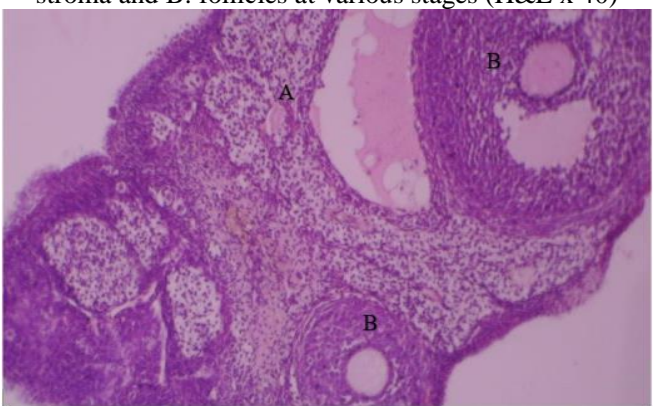

Plate 6: Higher magnification of same slide: A and B (H\&E x 100)

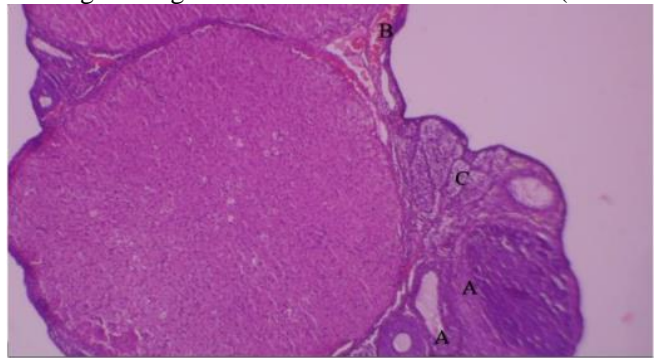

Plate 7: Rat ovary given nutmeg Day 7-14 and sacrificed on day 19 showing A: secondary follicles, B: stromal congestion and C: luteinized stroma (H\&E x 40)

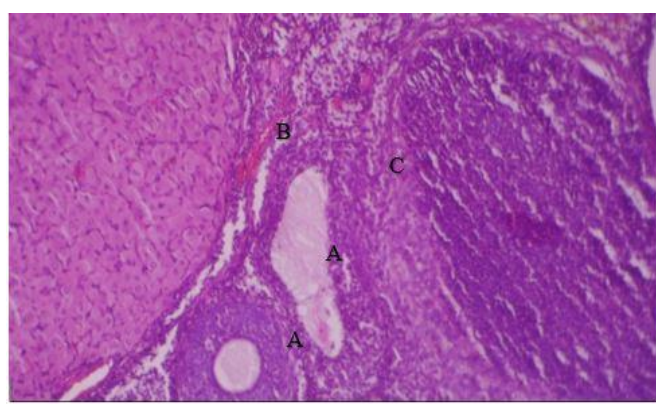

Plate 8: Higher magnification of same slide: A, B, C (H\&E x 100)

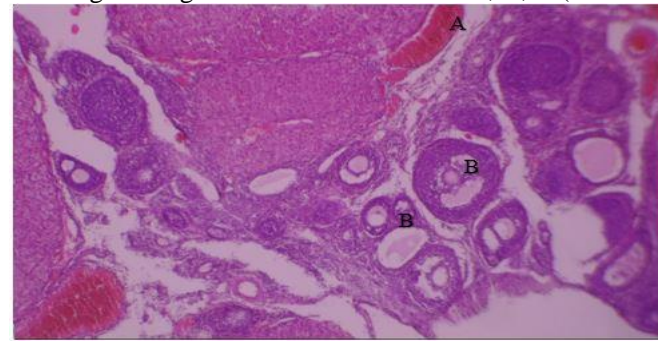

Plate 9: Rat ovary (pregestational phase) showing A: stromal congestion and B: increased folliculogenesis (H\&E x 40)

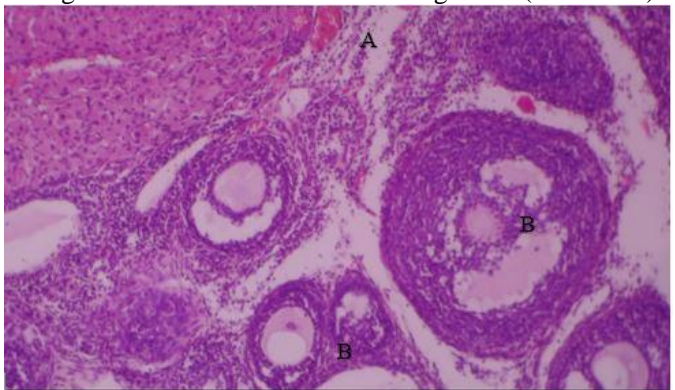

Plate 10: Higher magnification of same slide: A, B (H\&E x 100)

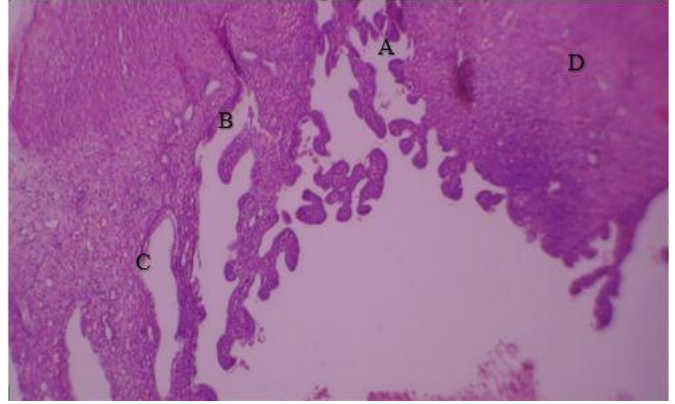

Plate 11: Rat uterus. Day 0-7 R-site showing A: endometrial lining forming villi, B: glandular cell hyperplasia, C: stromal cell hyperplasia and D: active congestion (H\&E x 40)

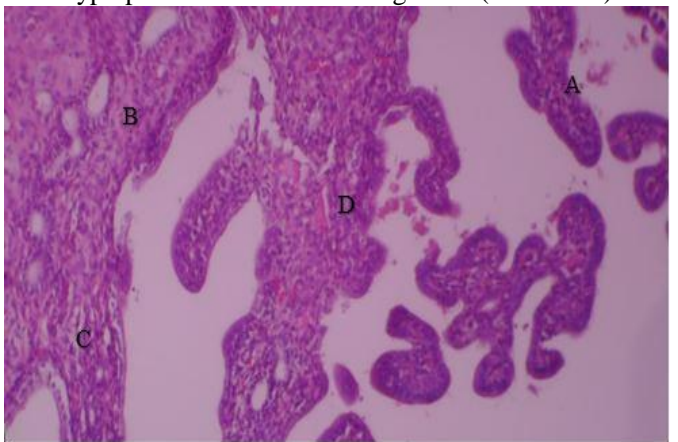

Plate 12: Higher magnification of same slide: $A, B$ and $C(H \& E x$ 100) 


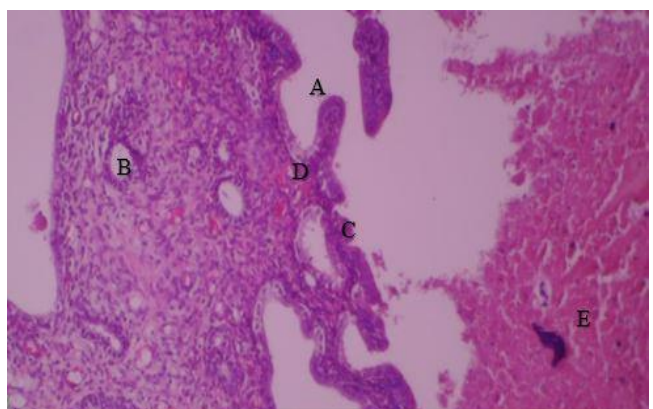

Plate 13: Rat uterus. Day 0-7 R-site showing A: villous endometrial lining, B: hypertrophic stromal cells, C: proliferating glands, D: active vascular congestion and E: haemorrhage (H\&E x 100)

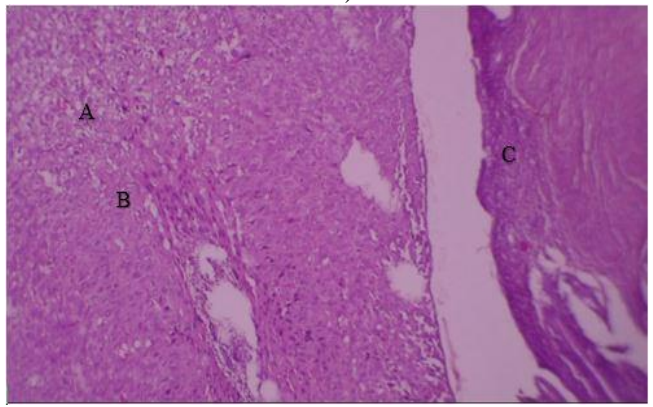

Plate 14: Rat uterus, Day 0-7 showing A: stromal cell vacuolation,

B: prominent nucleoli of stromal cells and C: endometrial lining thinning-atrophy (H\&E x 40)

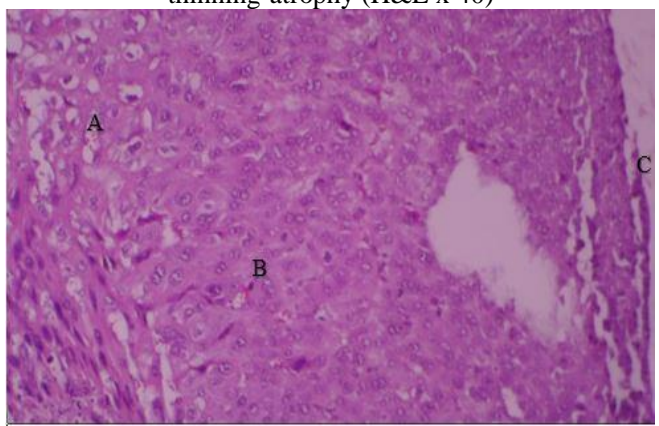

Plate 15: Higher magnification of same slide: A, B, C (H\&E x 100)

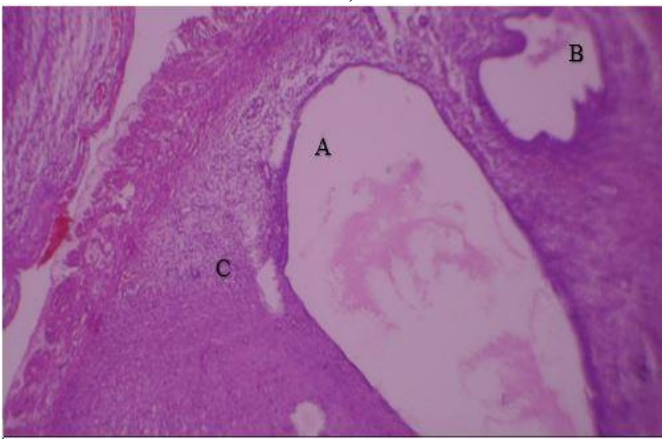

Plate 16: Rat uterus. Day 0-7 showing A: endometrial thinning and cavity containing blood $\mathrm{B}$ : endometrial glands distortion and C: atrophic endometrial glands (H\&E x 40)

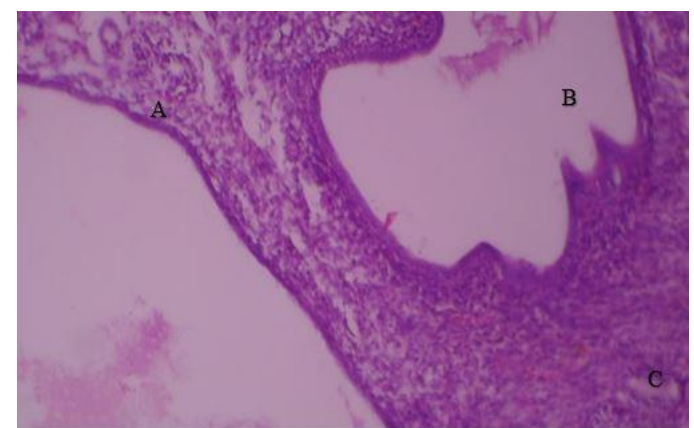

Plate 17: Higher magnification of same slide: A, B and C (H\&E x 100)

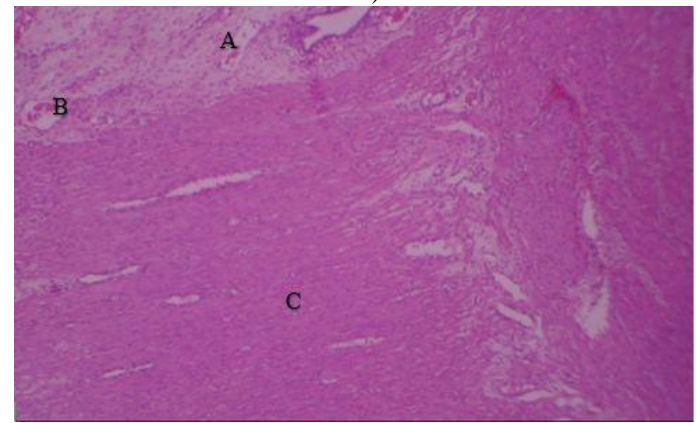

Plate 18: Rat uterus. Day 7-14 space showing A: myxoid stroma, B: stromal congestion and C: myometrial hypertrophy (H\&E x 40)

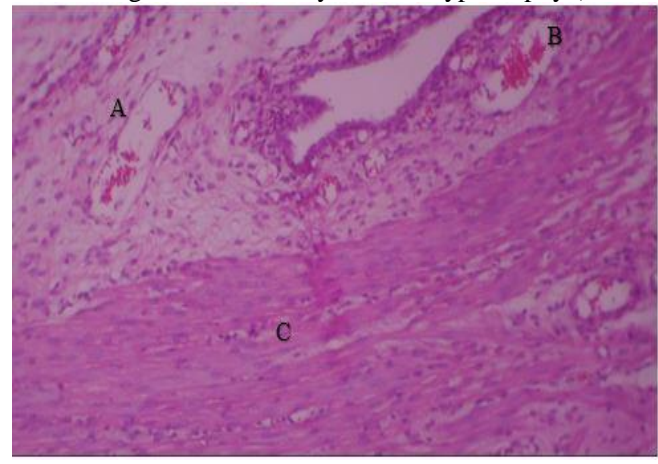

Plate 19: Higher magnification of same slide: A, B and C (H\&E $x$

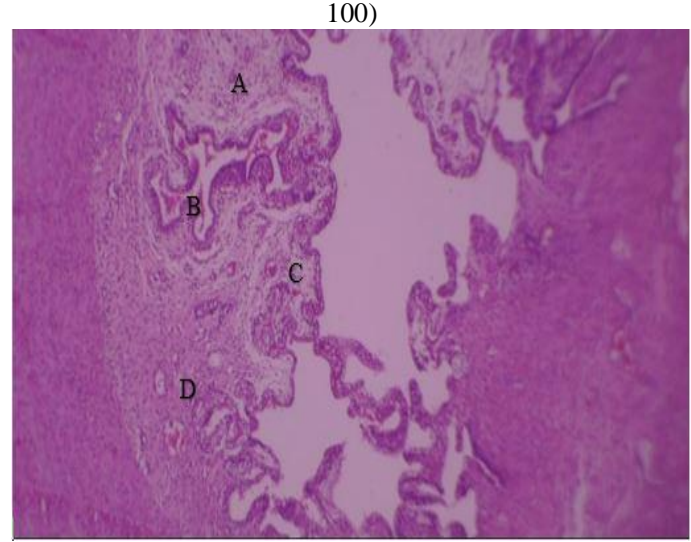

Plate 20: Rat uterus. Day 0-7 space showing A: myxoid stroma, B: blood in cavity, C: stromal congestion and D: glandular atrophy (H\&E x 40) 


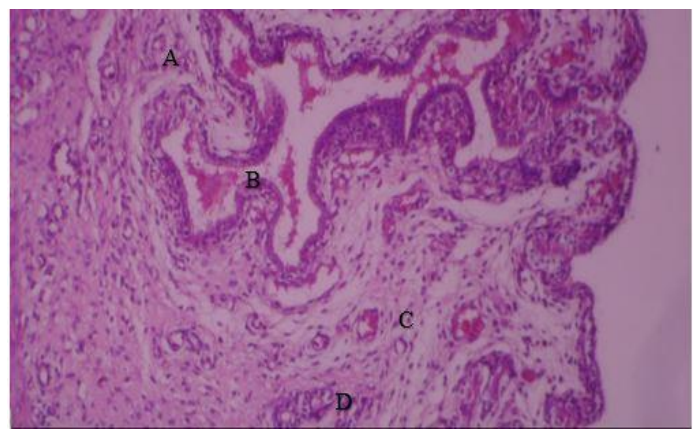

Plate 21: Higher magnification of same slide: A, B, C and D (H\&E x 100)

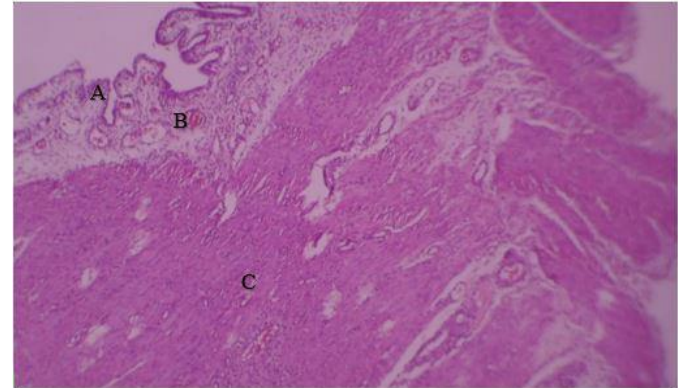

Plate 22: Rat uterus. Day 7-14 space showing A: myxoid stroma, $\mathrm{B}$ : congestion and C: myometrial hypertrophy (H\&E x 40)

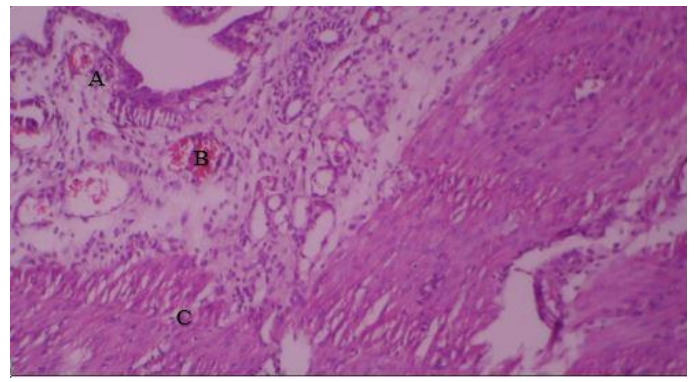

Plate 23: Higher magnification of same slide: A, B and C (H\&E $x$ 100)

Medicinal plants have been widely used to enhance or regulate fertility in females. The beneficial effects of medicinal plants on female fertility include stimulation of normal pituitary response of gonadotropin releasing hormone $(\mathrm{GnRH})$, improved normal pulsatile secretion of FSH and $\mathrm{LH}$, induction of ovulation, enhanced secretion of steroid hormones in ovarian cell, possessed estrogenic and progesteronic effects, and directly regulate ovarian function, at least in part, by inducing the secretion of cytokine (Ushiroyama, 2003; Yasui et al., 2003). On the other hand, some plants are also used as contraceptives in females. The sites of action of antifertility effects of medicinal plants in females include the hypothalamus, the anterior pituitary, the ovary, the oviduct, the uterus and the vagina. Medicinal plants impact fertility by various mechanisms of actions, including modulation of luteinizing hormone ( $\mathrm{LH})$ and follicle stimulating hormone $(\mathrm{FSH})$, decreasing their secretions and inhibiting follicles maturation and ovulation, inhibiting process of development of ovum and endometrium, inhibiting implantation and having abortifacient effects (Williamson et al., 1996; Brinker, 1997). There is a dearth of research on the effects of Myristica fragrans on pregnancy outcomes. Nevertheless, $M$. fragrans (nutmeg) is a plant that has been reported to possess antifertility effects (Hallström and Thuvander, 1997; Kakar et al., 2018). Despite the fact that $M$. fragrans is a widely used plant in culinary purpose, little is known about its safety. Bio-resource derived from medicinal plants can be useful but might have serious dose-related side effects, carry with them specific risk factors which can lead to increased vulnerability to health difficulties (Kamsu-Foguem and Foguem, 2014). In this study, the oral treatment of Wistar rats with $1500 \mathrm{mg} / \mathrm{kg}$ body weight of $M$. fragrans caused a significant decrease in the body weight of the treated rats, with respect to the control group during the embryonic phase of pregnancy. This is in harmony with findings by Agarwal et al (2009), who conducted a similar study and reported that the oral treatment of Myristica fragrans oil caused a significant change in the body weight of the treated rats with respect to the initial body weight. Comparable results were observed with other parameters (litter size and pup weight), as seen in Tables 2, 3, 4 and 5. The ovarian follicle is the fundamental unit of the ovary. It contains the oocyte that may eventually ovulate, undergo fertilization and form an embryo. It also provides the steroid and protein hormones required for maintenance of the ovarian cycle, the secondary sex characteristics and preparation of the uterus for implantation (Findlay et al., 2018). The depletion of ovarian follicles below a threshold number significantly reduces the possibility of pregnancy and this is irreversible because oogonial stem cells disappear after birth (Faddy et al., 1992). However, in our study, the results of the morphometry showed there was no significant difference in the number of ovarian follicles at the various stages of pregnancy when the treated groups were compared to the control group.

Uterine glands are essential for pregnancy because they secrete or transport bioactive substances that regulate uterine receptivity for blastocyst implantation. Mouse models with substantially reduced or absent uterine/endometrial glands exhibit a subfertile or infertile phenotype due to defects in blastocyst implantation (Kelleher et al., 2016). Filant and Spencer (2013) also hypothesized that uterine glands and their secretions have an important biological role in blastocyst implantation and stromal cell decidualization in the uterus. According to Hempstock et al (2004), morphologically, the endometrial glands are best developed and most 
active during early human pregnancy. Notwithstanding, in our research, the results of the morphometry showed there was no significant difference in the number of endometrial/uterine glands at the various stages of pregnancy when the treated groups were compared to the control group. This could be a testament to the antifertility effects of M. fragrans. Endometrial atrophy (as observed in several photomicrographs) usually results from loss of ovarian function and it is characterized by a reduction in the thickness of the endometrium and loss of endometrial glands (Foster, 2017), which was also recorded in our study.

Conclusion: This study therefore demonstrated that alcohol extract of Myristica fragrans has the potential to serve as a possible contraceptive agent in view of its anti-fertility effect, which could be beneficial in fertility management.

\section{REFERENCES}

Agarwal, M; Chauhan, A; Gehani, T (2009). Effects of Myristica fragrans oil on the reproductive organs of male albino rats. Pharm Biol, 47(6): 509-515

Brenner, N; Frank, OS; Knight, E (1993). Chronic nutmeg psychosis. J Royal Soc Med, 86(3): 179.

Brinker, F (1997). Inhibition of endocrine function by botanical agents, Antigonadotropic activity. Bri J Phytother, 4: 123-145

Calixto, JB (2000). Efficacy, safety, quality control, marketing and regulatory guidelines for herbal medicines (phytotherapeutic agents). Bra J Med Biol Res, 33(2): 179-189

Cronquist, A; Takhtadzhian, AL (1981). An integrated system of classification of flowering plants. Columbia university press, 499-501

De Milto, L; Frey, RJ (2019). "Nutmeg." Gale Encyclopedia of Alternative Medicine. Retrieved June 26, 2020 from Encyclopedia.com: https://www.encyclopedia.com/medicine/encyclo pedias-almanacs-transcripts-and-maps/nutmeg

Drury, RA; Wallington, EA; Cancerson, R (1976) Carlton's Histopathological Techniques. 4th Edition, Oxford University Press, Oxford, London, New York

Eze, GI; Akonoafua, KA (2019) Effects of Ethanol Leaf Extract of Lawsonia inermis Linn. on Carbon Tetrachloride-Induced Liver Injury in Adult Wistar Rats. Trop J Nat Prod Res, 3(8): 252-260
Faddy, MJ; Gosden, RG; Gougeon, A; Richardson, SJ; Nelson, JF (1992). Accelerated disappearance of ovarian follicles in mid-life: implications for forecasting menopause. Human Reprod, 7(10): 1342-1346

Filant, J; Spencer, TE (2013). Endometrial glands are essential for blastocyst implantation and decidualization in the mouse uterus. Bio Reprod, 88(4): 93-1

Findlay, JK; Kerr, JB; Britt, K; Liew, SH; Simpson, ER; Rosairo, D; Drummond, A (2018). Ovarian physiology: follicle development, oocyte and hormone relationships. Anim Reprod (AR), 6(1): 16-19

Foster, RA (2017). Female reproductive system and mammae. In Path Basis Vet Dis, 1147-1193

Hallström, H; Thuvander, A (1997). Toxicological evaluation of myristicin. Nat Tox, 5(5): 186-192

Hempstock, J; Cindrova-Davies, T; Jauniaux, E; Burton, GJ (2004). Endometrial glands as a source of nutrients, growth factors and cytokines during the first trimester of human pregnancy: a morphological and immunohistochemical study. Reprod Biol Endocrin, 2(1): 58

Joseph, J (1980). The nutmeg: its botany, agronomy, production, composition, and uses. J Plant Crops, 8(2): 61-72

Kakar, S; Shah, M; Jain, R (2018). Some medicinal plants with anti-fertility potential: a current status. J Basic Clin Reprod Sci: 7(2)

Kamsu-Foguem, B; Foguem, C (2014). Adverse drug reactions in some African herbal medicine: literature review and stakeholders' interview. Int Med Res, 3(3): 126-132

Kelleher, AM; Burns, GW; Behura, S; Wu, G; Spencer, TE (2016). Uterine glands impact uterine receptivity, luminal fluid homeostasis and blastocyst implantation. Sci Rep, 6(1): 1-18

Lahlou, M (2013). The Success of Natural Products in Drug Discovery. Pharmacol \& Pharm, 4(3A): 1731.

Nagano, I (2009). Myristica fragrans: an exploration of the narcotic spice. The Entheogen Rev. Vernal. 
Odebiyi, OO; Sofowora, EA (1978). Phytochemical screening of Nigerian medicinal plants II. Lloydia, 41(3): 234-246

Olajide, OA; Ajayi, FF; Ekhelar, AI; Awe, SO; Makinde, JM; Alada, AA (1999). Biological effects of Myristica fragrans (nutmeg) extract. Phytother Res: An Int J Devoted Pharmacol Toxicol Evaluation Natl Prod Derivatives, 13(4): 344-345.

Prabuseenivasan, S; Jayakumar, M; Ignacimuthu, S (2006). In vitro antibacterial activity of some plant essential oils. BMC Comp Alt Med, 6(1): 18.

Schulz, V; Hänsel, R; Tyler, VE (2001). Rat Phytother: a physician's guide to herbal medicine. Psychology Press.

Ushiroyama, T (2003). Endocrinological actions of Unkei-to a herbal medicine, and its clinical usefulness in anovulatory and/or infertile women. Reprod Med Biol, 2(2): 45-61.
Williamson, EM; Okpako, DT; Evans, FJ (1996). Selection, Preparation and Pharmacological Evaluation of Plant Material, Volume 1 (Vol. 1). John Wiley \& Sons.

World Health Organization (2005). National policy on traditional medicine and regulation of herbal medicines: Report of a WHO global survey

Yasui, M; Matsui, S; Laxmi, YS; Suzuki, N; Kim, SY; Shibutani, S; Matsuda, T (2003). Mutagenic events induced by 4-hydroxyequilin in supF shuttle vector plasmid propagated in human cells. Carcinogen, 24(5): 911-917.

Zhang, J; Onakpoya, IJ; Posadzki, P; Eddouks, M (2015). The safety of herbal medicine: from prejudice to evidence. Evidence-based Comp Alt Med, 316706-316706. 